\title{
When the Silence Speaks: The Smile
}

\author{
Maria do Rosário Dias, Letícia Garcia Naben, Ana Lúcia Monteiro, Ana Ferreira, \\ Valter Pedroso Alves, Ana Delgado
}

Unidade de Investigação-Centro de Investigação Multidisciplinar em Psicologia da Saúde Egas Moniz (CIMPSEM); Egas

Moniz-Cooperativa de Ensino Superior, Monte de Caparica, Portugal

Email: mariadorosario.dias@gmail.com

How to cite this paper: do Rosário Dias, M., Naben, L.G., Monteiro, A.L., Ferreira, A., Alves, V.P. and Delgado, A. (2018) When the Silence Speaks: The Smile. Journal of Biosciences and Medicines, 6, 13-20. https://doi.org/10.4236/jbm.2018.611002

Received: October 17, 2018

Accepted: November 13, 2018

Published: November 16, 2018

Copyright (c) 2018 by authors and Scientific Research Publishing Inc. This work is licensed under the Creative Commons Attribution International License (CC BY 4.0).

http://creativecommons.org/licenses/by/4.0/

(c) (i) Open Access

\begin{abstract}
Background: Understanding the importance, value and self-image that the smile represents in the daily life of the individual remains a subject of high scientific interest. Aim: The present qualitative and exploratory study aims at understanding the importance of the self-perception of the mouth and smile on the mental representation of self-image and the well-being of the individual. Materials and Methods: The convenience sample consisted of 151 children and youngsters of both genders, ages $8-24$ years, who used an orthodontic appliance and were invited to draw two portraits of their mouth/smile. Results: The results suggest differences in the mental representation of the mouth and the smile, namely in the investment of the drawings before and after the use of the orthodontic appliance, as well as in the expressiveness and manifestation of emotions. Discussion and Conclusions: The results suggest that the main reason that leads participants to the treatment is related to aesthetic and functional issues in which the maximizing of the mental representation of the Orthodontic Smile emerges as a new categorization of the perfect smile.
\end{abstract}

\section{Keywords}

Mental Representation, Orthodontic Smile, Aesthetic Smile, Drawing Content Analysis

\section{Introduction}

The face is the part of the human body that portrays intended actions and expressions, denoting or externalizing feelings and emotions [1]. The expression of the face is pragmatic, since it is at this level that much of the individuals' affection is transmitted in the interaction and in the bonding with Others.

Among these facial expressions is the smile [2], the first psychic organizer, vi- 
tal for the construction of the self-image of the individual. Understanding the importance, value and self-image that the smile represents in the daily life of the individual remains a subject of high scientific interest. Furthermore, the aesthetic harmony that the smile provides is of the utmost importance, since having an attractive face promotes the individual's social accepted in his circles of coexistence [3] [4]. In fact, the gift of affection expressed through the smile is of difficult measurable empirical control, which emphasizes the importance of the ability in reading patient's facial expression through non-verbal language, in the therapeutic setting of Dental Medicine [5]. In fact, in a research project carried out by the Faculty of Dentistry of the National Autonomous University of Mexico, which studied the perception of the aesthetic parameters of the smile perceived by both Dentists and Patients, it was verified that the unaesthetic smile variable was the only one with a high concordance of results both for Dentists and Patients. This simultaneously emphasizes the bias in terms of the perception of orthodontic treatment's results between Dentists and Patients and the high degree of difficulty in the empirical measuring of the "smile" category [4].

Thus, a panoply of analytical principles regarding the "smile" category need to become incorporated in the field of Dental Medicine Orthodontics [6], in order to obtain enhanced clinical results. Nevertheless, in the concept of aesthetics is underlined a subjective perception of the beauty concept operated by the subject [7], in which the symmetry of the smile plays an important role in the perception of the beauty of the face [8].

Indeed, in spite of the numerous references found in the literature review that highlight the importance of the functional and biomechanical determinants of malocclusion as a symptomatic diagnosis, there is still a shortage of empirical studies that combine the problem of malocclusion to the subject's self-image perception of the face in terms of the individual's psychosocial context [9] [10], insofar as the orthodontic treatment leads to notorious changes in the subject's intrapsychic experience.

The present study addresses this gap, aiming at understanding the importance of the self-perception of the mouth and smile in the mental representation of the individual's self-image perception of the face and in his well-being.

\section{Materials and Methods}

An empirical study of descriptive and exploratory nature was carried out to access the self-perception of the mouth and smile in the mental representation of the individual. The methodological strategy was of the qualitative kind, through the content analysis of a collection of Patients' drawings, combined with quantitative parameters.

The convenience sample consisted of 151 children and youngsters [11] of both genders, ages 8 - 24 years, who used an orthodontic appliance for 6 months (6 M) to 1 year $(1 \mathrm{Y})$, treated at the Egas Moniz University Clinic (Table A1). Patients were invited to produce two portraits (drawings) of their mouth/smile 
based on the following questions: 1)" What was your mouth like before you had the orthodontic appliance?" (Moment 1 (M1)); and 2) "How do you think your mouth will be when you remove the orthodontic appliance?" (Moment 2 (M2)). In addition, all participants answered a socio-demographic inquiry and provided a written answer to the question: "Why do you use an orthodontic appliance?"

According to the selected sample, 302 valid drawings were collected and analyzed, 151 of which representing M1 ("What was your mouth like before you had the orthodontic appliance?") and 151 of which representing M2 ("How do you think your mouth will look like when you remove the orthodontic appliance?"). A qualitative content grid for the analysis of the 302 drawings was originally designed, to study its pictorial representations. Four categories were created in the content analysis grid, e.g., 1) smile, 2) drawing of the figure, 3) appearance and 4) teeth. To further detail the content analysis, twelve subcategories were created, e.g., 1) size, 2) contours/limits, 3) opening of the mouth, 4) lips, 5) jaw, 6) with detail, 7) fractured, 8) with diastema, 9) crooked, 10) straight, 11) in saw and 12) well positioned.

With the purpose of knowing which smiles denounced Patients' affection and well-being, the categorization of the smile of Freitas-Magalhães was used [12] [13]. Through the content analysis grid created for the Patients' drawings, two types of smile were considered regarding the psychological perception of affection denounced by the smile: 1) "Broad Smile", which was considered to be the closest to the concept of happiness; and 2) "Superior Smile", which revealed a visual necessity of connection with other individuals in social contexts.

The statistic treatment of the descriptive data was analyzed using the software SPSS-Statistical Package for the Social Sciences IBM SPSS Statistics 23 for Windows.

The use of drawings a projective technique (instrument) in this empirical study was chosen as a preferred methodological strategy, insofar as drawings could be considered as the first form of cognitive-emotional expression and a basic and universal form of intrapsychic language. The use of the "pictorial drawing" instrument for research purposes of qualitative nature has been used as a methodological guideline of choice in research projects conducted in the field of Health Sciences' Studies [3] [14].

As a criterion of objectivity with regard to the task proposed to the selected subjects, they were asked to portray in their drawings only the mouth/smile and not other parts of the face, as to limit the appeal to draw the face, thus centering the analysis' object empirical focus on the smile [15].

\section{Results and Discussion}

The results suggest differences in the mental representation of the mouth and the smile, namely in the investment of the drawings before (M1) and after (M2) the use of the orthodontic appliance, as well as in the expressiveness and manifestation of emotions in these two moments. 
According to the appearance category, namely in the opening of the mouth subcategory, there was a decrease in the pictorial representation of the semi open mouth in M2, evidenced in drawings with more pronounced labial commissures at the level of the lips and showing a complete visualization of the upper and lower dental arches. Such is corroborated by the teeth and drawing of the figure categories (Figure 1) as both present a greater number of exposed teeth. In addition, more invested drawings were presented in the smile category in M2, when compared to M1.

The results also suggest that the main reason that led Patients to orthodontic treatment is related rather to functional issues than aesthetic ones, contrary to the results obtained in two studies carried out by Gonçalves and Torres at the University Clinic Egas Moniz-Portugal, which pointed to the aesthetic component and the quest for the "perfect smile" as the leitmotiv for the demand of orthodontic treatment in Dental Medicine [9] [10].

After the completion of the content analysis of the written answers to the question "Why do you use an orthodontic appliance?", in which a total of 103 written answers were collected (68.67\%), results suggest the main reason for the use of orthodontic appliance to be related to the functional well-being of the oral cavity. This seems to be corroborated by the content analysis of drawings in M2, revealing the presence of a broad smile $(\mathrm{M} 2=86.1 \%)$ and well-being (Figure 2), this emphasizing the "Broad Smile" as the closest to the concept of happiness [12].

The results also reveal differences in the self-perception of the mouth after the use of the orthodontic appliance (M2), namely by more invested drawings, more detailed and complete drawings and drawings with straight mouths and more aligned teeth. This fact may be connoted to the timing of the questionnaire in the treatment pathway $(6 \mathrm{M}-1 \mathrm{Y})$ suggesting that subjects may have a clinically induced speech about the Orthodontic Smile.

Likewise, the results point to the fact that the smile category (Figure 3 ) is predominantly illustrated with the teeth category (in terms of dental arcades) in detriment of the absence of the lips subcategory ( $\mathrm{M} 1=70.9 \%$; $2=70.8 \%$ ), with an exacerbation of the upper and lower dental arch. This suggests the concern of subjects regarding the oral health of teeth, seen as clinical entities that constitute the dental arcades.
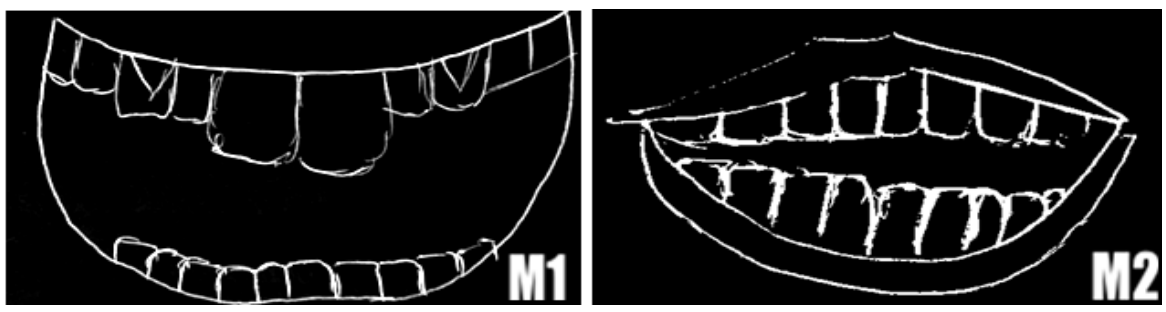

Figure 1. Drawings from one Patient which illustrates the fact that there are more invested drawings represented in the category smile in M2, when compared to M1. 


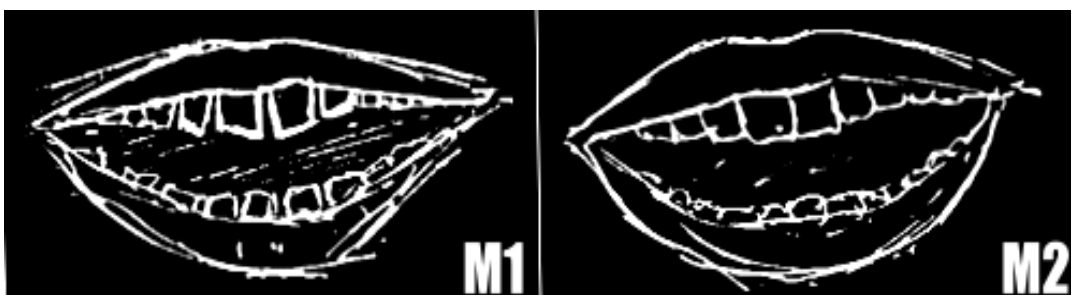

Figure 2. Drawings from another Patient which illustrates the presence of a broad smile, revealing well-being.

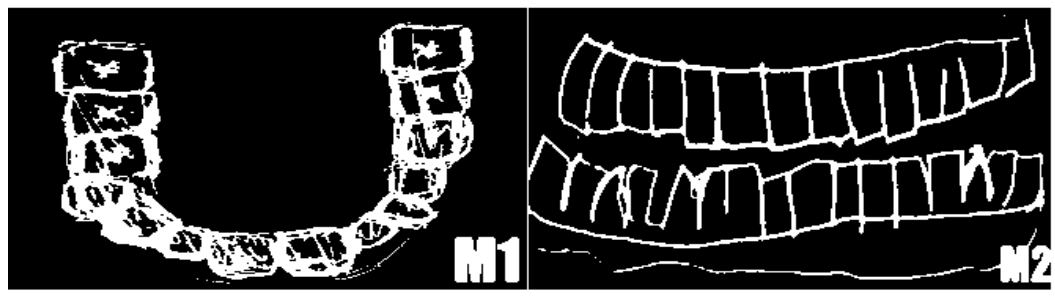

Figure 3. Drawings of a Patient which illustrates dental arcades converted to jaws and absence of lips in M1 and M2.

In this line of thought, the execution of the task (focused on the teeth category) was correctly perceived by the sample subjects, supported by the fact that only one of the subjects has drawn the teeth category with an orthodontic appliance applied.

Regarding the subcategory opening of the mouth, the results obtained suggest a decrease of the mouth percepts that were drawn as semi-open $(\mathrm{M} 1=41.1 \%$, $\mathrm{M} 2=27.8 \%)$ and closed $(\mathrm{M} 1=13.2 \%, \mathrm{M} 2=25.2 \%)$, which means that in $\mathrm{M} 2$ the labial commissures are drawn in a clearly more pronounced way at the level of the lips (Figure 4) and providing a complete visualization of the upper and lower dental arches.

In relation to the lips subcategory, the percentage of the upper and lower lips pictorially represented by the subjects shows an increase of $2.7 \%$ from M1 to $\mathrm{M} 2$. There was also a decrease in the representation of fine lips (M1 $=6.6 \%$, M2 $=2 \%)$ and thick lips $(\mathrm{M} 1=4 \%, \mathrm{M} 2=2.6 \%)$ compensated by a notorious increase in the representation of normal lips ( $\mathrm{M} 1=16.5 \%, \mathrm{M} 2=21.9 \%)$ in the percepts drawn by the subjects in $\mathrm{M} 2$.

The teeth category is the one that shows the most significant changes between M1 and M2. The most striking changes are reflected at the level of the fractured, with diastema, crooked, straight and well positioned subcategories. Moreover, the fractured and straight subcategories (Figure 5) evidence a noticeable percentage decrease in $\mathrm{M} 2$, regarding the drawing of fractured teeth $(\mathrm{M} 1=5.3 \%$, $\mathrm{M} 2=0.7 \%)$ and crooked teeth $(\mathrm{M} 1=88.1 \%, \mathrm{M} 2=17.9 \%)$.

In parallel, there is a considerable percentage decrease from M1 to M2 in the with diastema $(\mathrm{M} 1=17.9 \%, \mathrm{M} 2=1.3 \%)$, crooked teeth $(\mathrm{M} 1=45.7 \%, \mathrm{M} 2=$ $2.6 \%$ ) and well-positioned $(\mathrm{M} 1=91.4 \%, \mathrm{M} 2=17.2 \%$ ) (Figure 6) subcategories, as a form of representation of reinvented smiles, after the use of the orthodontic appliance. 


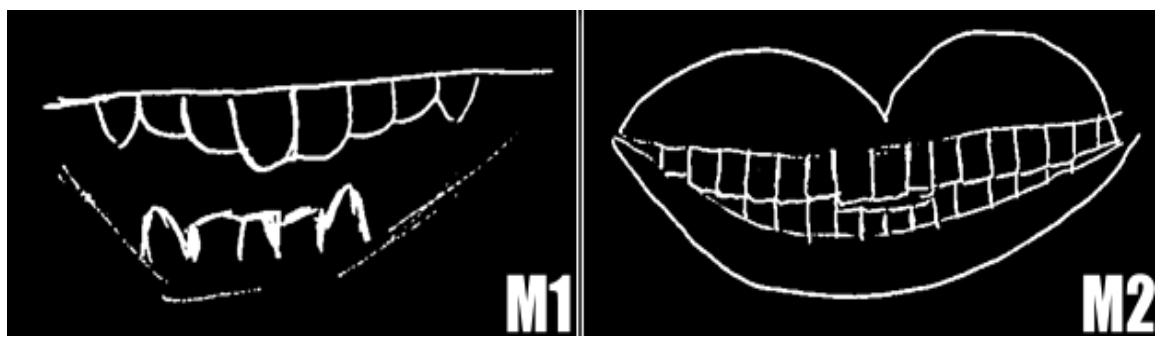

Figure 4. Drawings from a Patient which illustrates the decrease of the opening of the mouth subcategory, from M1 to M2.

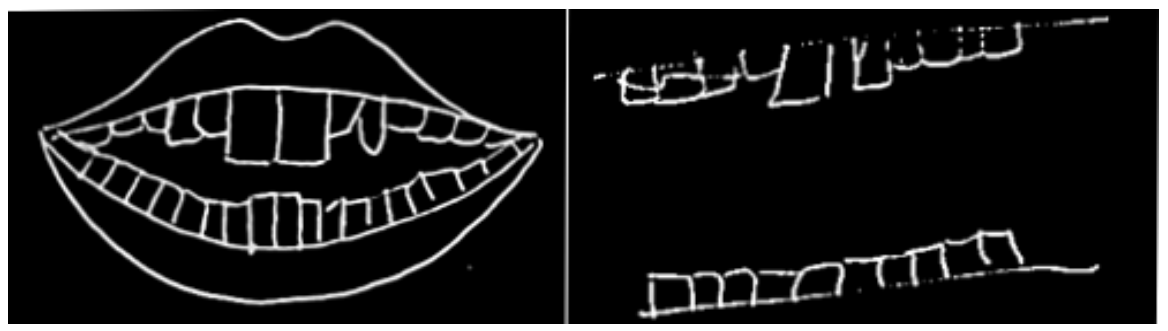

Figure 5. Decrease in predominance of fractured and crooked teeth illustrated by the drawing from different Patients in M2.
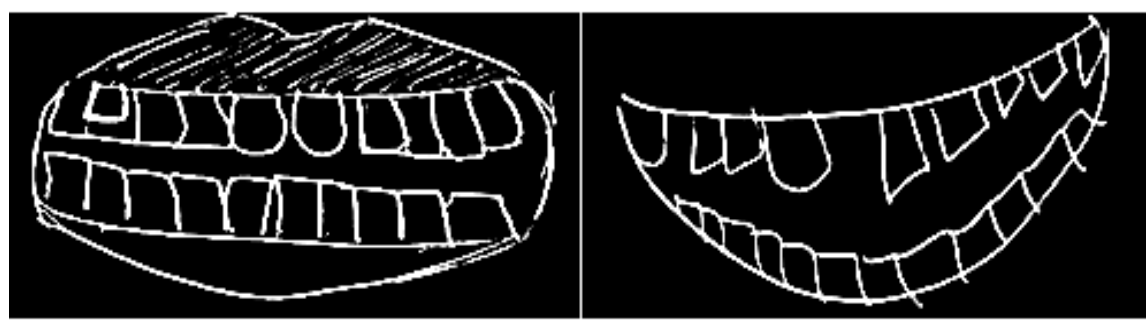

Figure 6. Drawing from different Patients which illustrates badly positioned teeth with visible diastemas in M1.

\section{Conclusions}

The aesthetic harmony that the smile provides is of the utmost importance for Patients, since having an attractive face promotes the individual's acceptance in his psychosocial context. It should be noted that when subjects were submitted to Orthodontic treatment, they seemed to associate the smile category to the social display of a look with Perfect Teeth-the so-called Orthodontic Smile-in clear contradiction to the Perfect Smile, which was connoted to the subcategory lips.

These results present a contribution to the understanding of the importance of the Mouth and Smile in the self-image and psychic well-being of the individual, in which the broadening of the mental representation of the Orthodontic Smile emerges as a new form of categorization of the perfect smile.

\section{Conflicts of Interest}

The authors declare no conflicts of interest regarding the publication of this paper. 


\section{References}

[1] Dias, M.R. and Duque, A.F. (2010) Mens Sana in Corpore Sano: The Concept of Health and Illness in Childhood. IFPE-21 st Annual Interdisciplinary Conference. Psychoanalysis. Not the Same Old Song and Dance? Nashville, Tennessee, 29-31 October 2010, Conference Program/Abstract Membership Directory, 10.

[2] Ekman, P., Davidson, R.J. and Friesen, W.V. (1990) The Duchenne Smile: Emotional Expression and Brain Physiology II. Journal of Personality and Social Psychology, 2, 342-353. https://doi.org/10.1037/0022-3514.58.2.342

[3] Fávero, M.H. and Salim, C.M.R. (1995) A relação entre os conceitos de saúde, doença e morte: Utilização do desenho na colecta de dados. Psicologia: Teoria e Pesquisa, 11, 181-191.

[4] Mora, M.G., Serna, M.E.V. and Ledesma, A.F. (2015) Perception of Smile Aesthetics by Dental Specialists and Patients. Revista Mexicana de Ortodontia, 3, 13-21. https://doi.org/10.1016/j.rmo.2016.03.006

[5] Mendes, J.J., Dias, M.R., Neves, A.C., Ferreira, A., Maia, P., Silva, N. and Delgado, A. (2017) The Language of Silence in the Therapeutic Setting of Dental Medicine. $2^{\circ}$ Congresso International do CiiEM-Research and Innovation in Human \& Health Science, Monte da Caparica, Portugal.

[6] Singh, P.V. and Sharma, J.N. (2011) Principles of Smile Analysis in Orthodontics-A Clinical Overview. Health Renaissanse, 9, 35-39.

[7] Dávila, F.B. (2004) El arte en la medicina: las proporciones divinas. Revista de divulgación científica y tecnológica de la Universidad Autónoma de Nuevo León, 7, 150-156.

[8] Bolívar, L.Á.M. and Mariaca, B.P. (2012) La Sonrisa y sus dimensiones. Revista Facultad de Odontología Universidade de Antioquia, 23, 353-365.

[9] Gonçalves, S. (2011) O tratamento ortodôntico e a sua influência na auto-imagem do rosto do sujeito. Ph.D. Dissertation, Instituto Superior de Ciências da Saúde Egas Moniz, Monte da Caparica.

[10] Torres, J. (2011) A influência do género na adolescência em dentisteria operatória. Ph.D. Dissertation, Instituto Superior de Ciências da Saúde Egas Moniz, Monte da Caparica.

[11] Sawyer, S.M., Azzopardi, P.S., Wickremarathne, D. and Patton, G.C. (2018) The Age of Adolescence. The Lancet Child \& Adolescent Health, 2, 223-228. https://doi.org/10.1016/S2352-4642(18)30022-1

[12] Freitas-Magalhães, A. (2007) Expressão facial: O efeito do sorriso na percepção psicológica da afectividade. Revista da Faculdade de Ciências Humanas e Sociais da Universidade Fernando Pessoa, 4, 276-284.

[13] Freitas-Magalhães, A. (2009) A Psicologia do sorriso humano. 2nd Edition, Edições Universidade Fernando Pessoa, Porto.

[14] Gazzinelli, M.F.C., Silva, T.C., Rodrigues, R.Á., Araújo, E.G. and Bethony, J. (2008) Representações de crianças de zona rural sobre saúde e o pesquisador: A grande saúde e o grande outro. Revista de Enfermaria de Minas Gerais, 12, 153-161.

[15] Johnson, D.K. and Smith, R.J. (1995) Smile Esthetics after Orthodontic Treatment with and without Extraction of Four Premolars. American Journal of Orthodontics and Dentofacial Orthopedics, 108, 162-167. https://doi.org/10.1016/S0889-5406(95)70079-X 


\section{Appendix}

Table A1. Table with sociodemographic characteristics referring to the Patients of this study.

\begin{tabular}{|c|c|c|}
\hline & Frequency & Percentage (\%) \\
\hline \multicolumn{3}{|l|}{ Gender } \\
\hline Female & 75 & 49.7 \\
\hline Male & 75 & 49.7 \\
\hline \multirow[t]{2}{*}{ Not applicable } & 1 & 0.7 \\
\hline & Total 151 & 100 \\
\hline \multicolumn{3}{|l|}{ Age } \\
\hline 8 & 4 & 2.6 \\
\hline 9 & 1 & 0.7 \\
\hline 10 & 8 & 5.3 \\
\hline 11 & 7 & 4.6 \\
\hline 12 & 18 & 11.9 \\
\hline 13 & 11 & 7.3 \\
\hline 14 & 22 & 14.6 \\
\hline 15 & 21 & 13.9 \\
\hline 16 & 13 & 8.6 \\
\hline 17 & 12 & 7.3 \\
\hline 18 & 11 & 7.9 \\
\hline 19 & 6 & 4.0 \\
\hline 20 & 6 & 4.0 \\
\hline 21 & 3 & 2.0 \\
\hline 22 & 2 & 1.3 \\
\hline 23 & 2 & 1.3 \\
\hline \multirow[t]{2}{*}{24} & 4 & 2.6 \\
\hline & Total 151 & 100 \\
\hline
\end{tabular}

